\title{
Changes in Intraoperative and Postoperative Neural Response Telemetry in Cochlear Implant Users
}

\author{
Shahenda A. Moussa, Mostafa A. Aly, Mohamed Abd Al-Ghaffar \\ Audiology Unit, Department of Otorhinolaryngology, Sohag Faculty of medicine, Sohag \\ University
}

\begin{abstract}
Introduction: The cochlear implant directly stimulates the auditory nerve in deaf patients. Neural Response Telemetry (NRT) is used to record the response of the auditory nerve through thefeedback of the electrical signal. NRT does not need behavioral responses from very young

children for thresholds and comfort levels. The status of the cochlear nerve activation with

NRT was reviewed through intraoperative and postoperative neural responses.
\end{abstract}

Aim of the work: To detect any changes in intraoperative and postoperative neural response telemetry in cochlear implant users.

Patients and Methods:Thirty patients were implanted with a MED-EL device, Sonata II (Med-El, Innsbruck, Austria) at Sohag University hospital. Electrodes 2, 4, 6, 8, 9, 10, 11 and 12 were monitored intraoperatively. One month after surgery, the neural responses were investigated using the same electrodes as during the intraoperative procedures. The corresponding electrodes werethen checked again after another 3 months.Phase duration $30 \mu \mathrm{s}$, begin by amplitude 200cu increasing in steps each $100 \mathrm{cu}$ till get response or reaching maximum level 1200cu (intraoperative) or reached the uncomfortable level of the child (postoperative). Threshold of the neuronal response is calculated using linear equation function.

Results:There is significant improvement in thresholdsof NRTresponse postoperatively which was high intraoperatively. NRT threshold increase in postoperative follow up in comparison with first postoperative measurement but this increase is not statistically significant.

Conclusion: Absence of NRT response in some electrodes intraoperative does not mean that electrode must be out of function or outside the cochlea.

Keyword:Pre-op.vs Post-op., CI, NRT.

\section{Introduction}

Cochlear implantation provides the single most effective form of hearing rehabilitation in patients with bilateral severe to profound sensorineural hearing loss that is no longer responsive to amplification.Cochlear implantation plays a critical role in hearing restoration for those patients who are either born with sensorineural hearing loss (congenital) or in those who develop a significant sensorineural hearing loss throughout childhood (Bower and Martin 2008). 
Clark (2003) described the cochlear implant as a device that electrically stimulates the auditory nerve, bypassing the nonfunctional inner ear of children and adults with severe-to-profound hearing loss. Current cochlear implant systems consist of:a multichannel electrode array that is surgically implanted, and an external sound processing unit, usually worn behind the ear, that controls the implant over a transcutaneous link.

Grolman et al. (2009) reported that during the implantation, various parameters can be utilized to CI. In order toshow that its functioning properly and examine the integrity of the electrode in addition to measurement of ECAP signals through auditory nerve response telemetry (ART), neural response telemetry(NRT) and the excitation threshold of the stapedius muscle (ESRT).The most commonly used tool to examine CI function is impedance field telemetry (IFT).

According to Cosetti et al. (2010) neural response telemetry is routinely measured at the time of implantation. This gives us information regarding the electrical output of the implant, the response of the auditory system to electrical stimulation and preliminary device programming data.

Vargas et al. (2012) observed a slight reduction in impedance values during the first four weeks, followed by progressive increase that stabilized at about six months following CI activation.

\section{Aim of the work:}

This study is conducted to see that if there will be changes in neural response telemetry postoperative compared to that measured intraoperative.

Patients and Methods:

Patients:
Thirty patients (17 females, 13 males) were included in this study. The age of our patients ranged between 2 and 16 years, (mean $6.2 \pm 3.5$ years) were implanted with a MED-EL device, Sonata II (Med-El, Innsbruck, Austria) at Sohag University hospital. They all suffered from bilateral severe to profound sensorineural hearing loss.

\section{Methods:}

-Procedure:

First Informed written consent was taken from the parents before entrance of the operating room and study was approved by ethics committee in Sohagmedical university.

-ECAP recording:

The cochlear implant device used in this study consists of: receiver-stimulator, 12 intracochlear electrodes. The receiver-stimulator features a bi-directional telemetry system, which allows communication of data between the programming hardware and the implant using transcutaneous radio-frequency code.

1-Intra-operative recording of NRT:

Whole-nerve action potentials were evoked by electrical stimulation intraoperatively while stimulating over electrodes within the intracochlear array. The stimulus current limit was estimated at each electrode, and 9 steps (100 current levels each) from 200 to 1000 were performed as stimulation applied on a given intracochlear electrode.

The neuronal responses were recorded using the MEDEL telemetric system, type of implant SONATAti100, The implant records those potentials arising from nerve fibers local to the stimulation site from a neighboring recording electrode, amplifies them and encodes them for radio frequency (RF) transmission back to the speech processor. 
ECAP is extracted from the stimulus artifact using a subtraction method. ECAP recordings were obtained in operating room. The recordings were obtained at the end of the implant operation after the surgeon placed the skin flap over the implanted device. The surgeon positioned a transmitting coil over the internal device, using commercial Maestro 6.0.1 Build 5456.33222 software which allows insitu measurements of the ECAP by implementing the forward masking paradigm by using MAX coil.

The signal was processed by the subtraction method to differentiate between the stimulus artifact and the neuronal response. The relationship between the amplitude of the neuronal response and the stimulus levels was calculated.

electrode $n+1$ except electrode 12 was recorded from electrode11).

2-Post-operative recording of NRT:

ECAP recordings were obtained again on the first fitting of the device after the operation in the Sohag Cochlear Implant Unite while the patient was awake. ECAP was done at the same electrodes (no.2, no.4, no.6, no.8, no.9, no.10, no.11 and no.12), phase duration $30 \mu \mathrm{s}$, begin by amplitude 200cu increasing in
A linear regression line was fitted to these data. Using the equation of this linear function, the current level was calculated at which just no recordable neuronal response occurs ('zero amplitude'). This parameter is called tNRT (threshold of the neuronal response telemetry).

The stimulus used in the measurements was a biphasic current pulse, 30 $\mu \mathrm{s} /$ phase Minimum amplitude 200cu and maximum amplitude $1000 \mathrm{cu}$, of alteration: 25, measurement gap: 1ms, measurement delay125ms.ECAP recordings were made at eight stimulation sites (electrodes no.2, no.4, no.6, no.8, no.9, no.10, no.11 and no.12). The corresponding recording site was one electrodes apical to the stimulation site (i.e., the neural response to stimulation on electrode (n) was recorded from steps each $100 \mathrm{cu}$ till get response or reached the uncomfortable level of the child. Threshold of the neuronal response is calculated using linear equation function.

Two months later, neural response threshold of the same electrodes is measured with the same parameters starting with $200 \mathrm{cu}$ amplitude with 100 $\mathrm{cu}$ increments till get response or the uncomfortable level of the patient.

\section{Results}

\section{Comparison of NRT response (presence or absence) intraoperative, one month and three months postoperative among all electrodes under the study. 1-NRT results among electrodes $2,4,6$ and 8 :}

On comparison of the NRT response (presence or absence) intraoperative versus one month and three months post-operative for electrodes no. 2, 4, 6, and 8 (table 1)), there was significant difference at electrode (6) when comparing the response among the three groups (p-value) and in comparing the response between intraoperative and one month postoperative (p1), this means that there was significant improvement in the response of NRT of El.6 between the three groups and between intraoperative and one month postoperative. While there was no significant difference neither between intraoperative 
SOHAG MEDICAL JOURNAL Changes in Intraoperative and Postoperative Neural Response

and three months post-operative (p2), nor between one month and three months after implantation (p3).

Table (1): Comparison of the (NRT) state measured by electrode no.2,4,6 and 8 intraoperative, one month and three months after implantation $(\mathbf{N}=30)$.

\begin{tabular}{|c|c|c|c|c|c|c|c|}
\hline Response & $\begin{array}{l}\text { Intra-operative } \\
\text { No. }(\%)\end{array}$ & $\begin{array}{l}\text { One month No. } \\
(\%)\end{array}$ & $\begin{array}{l}\text { Three months } \\
\text { No. }(\%)\end{array}$ & P-value & P1 & $\mathbf{P 2}$ & P3 \\
\hline $\begin{array}{c}\text { El.2 presence } \\
\text { absence }\end{array}$ & $\begin{array}{l}25(83.3) \\
5(16.7)\end{array}$ & $\begin{array}{l}29(96.7) \\
1(3.3)\end{array}$ & $\begin{array}{l}28(93.3) \\
2(6.7)\end{array}$ & 0.168 & 0.195 & 0.424 & 0.5 \\
\hline $\begin{array}{c}\text { El.4 presence } \\
\text { absence }\end{array}$ & $\begin{array}{l}27(90) \\
3(10)\end{array}$ & $\begin{array}{l}30(100) \\
0(0)\end{array}$ & $\begin{array}{l}29(96.7) \\
1(3.3)\end{array}$ & 0.160 & 0.237 & 0.612 & 0.5 \\
\hline $\begin{array}{c}\text { El.6 presence } \\
\text { absence }\end{array}$ & $\begin{array}{l}25(83.3) \\
5(16.7)\end{array}$ & $\begin{array}{l}30(100) \\
0(0)\end{array}$ & $\begin{array}{l}29(96.7) \\
1(3.3)\end{array}$ & $0.024 *$ & $0.026^{*}$ & 0.195 & 0.5 \\
\hline $\begin{array}{c}\text { El.8 presence } \\
\text { absence }\end{array}$ & $\begin{array}{l}23(76.7) \\
7(23.3)\end{array}$ & $\begin{array}{l}28(93.3) \\
2(6.7)\end{array}$ & $\begin{array}{l}28(93.3) \\
2(6.7)\end{array}$ & 0.075 & 0.073 & 0.073 & 1 \\
\hline
\end{tabular}

\section{2-NRT results in electrodes number 9, 10, 11 and 12:}

There was significant difference at electrodes 9 and 10 when comparing the response among the three groups. Moreover, on comparing NRT response between intraoperative and one month after implantation and between intraoperative and three months after implantation there was statistical significant difference at electrodes 9 and 10 which means that there was significant improvement in the response of NRT in El 9 and 10 of the three groups, intraoperative and one month after implantation, and between intraoperative and three months after implantation (table 2).

Table (2): Comparison of the (NRT) state measured by electrode no.9,10, 11and12 intraoperatively, one month and three months after implantation $(\mathrm{N}=30)$.

\begin{tabular}{|c|c|c|c|c|c|c|c|}
\hline Response & $\begin{array}{l}\text { Intra-operative } \\
\text { No. }(\%)\end{array}$ & $\begin{array}{l}\text { One month No. } \\
(\%)\end{array}$ & $\begin{array}{l}\text { Three months } \\
\text { No. }(\%)\end{array}$ & P-value & P1 & P2 & P3 \\
\hline $\begin{array}{l}\text { El.9 presence } \\
\text { absence }\end{array}$ & $\begin{array}{l}22(73.3) \\
8(26.7)\end{array}$ & $\begin{array}{l}29(96.7) \\
1(3.3)\end{array}$ & $\begin{array}{l}29(96.7) \\
1(3.3)\end{array}$ & $0.004 *$ & $0.2 *$ & $0.02 *$ & 0.75 \\
\hline $\begin{array}{l}\text { El.10 presence } \\
\text { absence }\end{array}$ & $\begin{array}{l}21(70) \\
9(30)\end{array}$ & $\begin{array}{l}28(93.3) \\
2(6.7)\end{array}$ & $\begin{array}{l}30(100) \\
0(0.0)\end{array}$ & $0.001 *$ & $0.004 *$ & $0.002 *$ & 0.246 \\
\hline $\begin{array}{c}\text { El.11 presence } \\
\text { absence }\end{array}$ & $\begin{array}{l}19(63.3) \\
11(36.7)\end{array}$ & $\begin{array}{l}25(83.3) \\
5(16.7)\end{array}$ & $\begin{array}{l}26(86.7) \\
4(13.3)\end{array}$ & 0.063 & 0.072 & 0.061 & 0.5 \\
\hline $\begin{array}{l}\text { El.12 presence } \\
\text { absence }\end{array}$ & $\begin{array}{l}17(56.7) \\
13(43.3)\end{array}$ & $\begin{array}{l}22(70) \\
9(30)\end{array}$ & $\begin{array}{l}28(93.3) \\
2(6.7)\end{array}$ & 0.35 & 0.211 & 0.139 & 0.5 \\
\hline
\end{tabular}


SOHAG MEDICAL JOURNAL Changes in Intraoperative and Postoperative Neural Response

Vol. 21 No.3 october 2017

Shahenda A. Moussa

Comparison between NRT threshold intraoperative, one month and three months postoperatively:

On comparing thresholds of the 8 electrodes under the study, each intraoperative, one month and three months after implantation (table 3), there was significant difference in thresholds of El.2, 6,8,9and10 which denotes significant improvement in thresholds of NRT of electrodes 2 and 6 in comparing response intraoperatively, one month and three months postoperatively, and between threshold intraoperative and one month after implantation.

Table (3): Comparison of neural response telemetry threshold measured by the eight electrodes intraoperative, one month and three months after implantation.

\begin{tabular}{|c|c|c|c|c|c|c|c|c|}
\hline $\begin{array}{l}\text { Thresh } \\
\text { old }\end{array}$ & & $\begin{array}{l}\text { Intra- } \\
\text { operative }\end{array}$ & One month & $\begin{array}{l}\text { Three } \\
\text { months }\end{array}$ & P-value & P1 & $\mathbf{P 2}$ & $\mathbf{P 3}$ \\
\hline \multirow[t]{8}{*}{$\begin{array}{l}\text { Mean } \pm \\
\text { SD }\end{array}$} & $\underline{\text { El.2 }}$ & $\begin{array}{r}370.1 \\
\pm 134.8\end{array}$ & $\begin{array}{r}279.8 \\
\pm 133.02\end{array}$ & $\begin{array}{l}305.9 \\
\pm 137.3\end{array}$ & 0.017* & $0.014 *$ & 0.052 & 0.233 \\
\hline & $\underline{\text { El.4 }}$ & $\begin{array}{l}317.6 \\
\pm 120.9\end{array}$ & $\begin{array}{l}\text { 281.2 } \\
\pm 131.9\end{array}$ & $\begin{array}{l}316.8 \\
\pm 116.4\end{array}$ & 0.298 & 0.205 & 0.973 & 0.138 \\
\hline & $\underline{\text { El.6 }}$ & $\begin{array}{l}375 \\
\pm 166.8\end{array}$ & $\begin{array}{l}\mathbf{2 7 0 . 8} \\
\pm 135.1\end{array}$ & $\begin{array}{l}\mathbf{3 2 3 . 8} \\
\pm 151.5\end{array}$ & $0.004 *$ & 0.001* & 0.141 & 0.06 \\
\hline & $\underline{\text { El.8 }}$ & $\begin{array}{l}380.2 \\
\pm 153.9\end{array}$ & $\begin{array}{l}277.7 \\
\pm 121.9\end{array}$ & $\begin{array}{l}340.8 \\
\pm 126.02\end{array}$ & 0.008* & $0.002 *$ & 0.174 & 0.043* \\
\hline & $\underline{\text { El.9 }}$ & $\begin{array}{l}438.6 \\
\pm 172.7\end{array}$ & $\begin{array}{l}321.4 \\
\pm 119.9\end{array}$ & $\begin{array}{l}356 \\
\pm 175.8\end{array}$ & $0.001 * *$ & $0.002 *$ & 0.038* & 0.0142 \\
\hline & $\underline{\text { El.10 }}$ & $\begin{array}{l}487.9 \\
\pm 170.5\end{array}$ & $\begin{array}{l}392.8 \\
\pm 114.9\end{array}$ & $\begin{array}{l}\text { 380.8 } \\
\pm 155.3\end{array}$ & $0.015^{*}$ & 0.002* & $0.015 *$ & 0.675 \\
\hline & $\underline{\text { El.11 }}$ & $\begin{array}{l}353.6 \\
\pm 102.2\end{array}$ & $\begin{array}{l}356.9 \\
\pm 124.5\end{array}$ & $\begin{array}{l}\text { 343.8 } \\
\pm 151.2\end{array}$ & 0.798 & 0.885 & 0.792 & 0.662 \\
\hline & $\underline{\text { El.12 }}$ & $\begin{array}{l}286.2 \\
\pm 117.1\end{array}$ & $\begin{array}{l}285.8 \\
\pm 114.7\end{array}$ & $\begin{array}{l}297 \\
\pm 144.5\end{array}$ & 0.730 & 0.983 & 0.672 & 0.556 \\
\hline
\end{tabular}

In addition, there is significant improvement in electrode 8 in comparing thresholds intraoperative versus one month and three months postoperative, between intraoperative threshold and one month after implantation, in addition to significant difference (improvement) between threshold one month and three months after implantation.

Results also revealed highly significant improvement in electrode 9 in comparing thresholds intraoperatively, one month and three months postoperatively.Moreover, there was significant improvement between intraoperative threshold and one month after implantation and between threshold intraoperative and 3 months after implantation. 
There is significant improvement in threshold of NRT of electrode 10 in comparing thresholds among intraoperative, one month and three months postoperatively, intraoperative and one month after implantation, between threshold intraoperative and 3 months after implantation.

Comparing threshold of NRT one and three months postoperatively there was increase in thresholds of E.2, El.4, El.6, El.8 and El.12; however this increase was not statistically significant except at El.8.

\section{Discussion}

All subjects under the study were evaluated for neural response telemetry 3 times, intraoperative, one month and 3 months after implantation for electrodes 2, 4, 6, 8, 9, 10, 11 and 12 .

* Comparison of NRT response (presence or absence) intraoperative, one month and three months postoperative among all electrodes under the study:

On measuring intraoperative NRT for electrodes 2, 4, 6, 8, 9, 10, 11 and 12:

Not all the electrodes had NRT response; NRT response was absent in 5 children for El.2, in 3 children for El.4, in 5 children for El.6 ,in7 children for El.8, in 8 children for El.9, in 9 children for El.10,in11 children for El.11 and 13 children for El.12 (table 1 \&2).

The majority of the electrodes who had no response were the basal electrodes $(9,10,11$ and 12$)$ which may be due to air bubbles, oedema of the tissues or due to manipulation of the implant (Cosetti et al .,2012).

On follow up of the responses of the electrodes one month after the implantation; four of children who had no response in El.2 became responsive, all children had response for El.4 and 6, only2 children had no response for El.8 and 10 , one child had no response for El.9, 5 children had no response for El.11 and 9 children had no response for El.12 (table 1\&2).In addition, Significant improvement was found at El.6, 9 and 10.

To know whether this improvement is solid or not, NRT was measured for second time, three month postoperatively. Result were that one of children who had response one month after operation became non responsive three months postoperatively, also one of responsive children became non responsive three months after implantation at EL.4 and 6 (table 1\&2).

No change was found in the response of El.8 and .All children had response for El.10.One of the children who had no response for El.11 became responsive. Only two of children had no response for El.12.

Significant improvement was found mainly at El.6, 9 and 10 (the middle electrodes).

Su et al. (2008) agreed with this result and attributed absence of response intraoperatively owing to interaction between surface chemistry of the electrode and electrical stimulation when implant is initially activated ,this is due to the development of tissue growth around the electrode affected by protein absorption (initial increase) and electrical stimulation (dispersion of this surface layer).

Also Goehring et al. (2013) agreed with this result and assumed that air bubbles, oedema of tissue and thickness of skin flap above electronic package may also affect initial measurement.

While Cosetti et al. (2012) refer that due to difference in the interactive electrical conduction between the tissue and the electrodes in the cochlea. 
Chen et al. (2013)attributed absence of response on first measurement postoperative then appearance of response later may be due to hematoma, infection or flap swelling

So, appearance of response in electrodes postoperatively is with assumption of each (Su et al. 2008), (Goehring et al. 2013), (Cosetti et al. 2012) and (Chen et al. 2013).

However, some electrodes which had no response intraoperatively, had no response postoperatively, two children had no response for El.2 , 8and12one children for El.4, 6 and 9, and four children had no response for El.11.

Also, some electrodes which had response became non responsive, one child became non responsive for El.2,one child had no response for El.4,and another one for El.6 which may be due to fibrous growth from the insertion of the electrode into the cochlea and surface chemistry of the electrode.

Comparison between NRT threshold intraoperative, one month and three months postoperatively:

Thresholds of all electrodes were measured intraoperatively and followed up one and three months postoperatively to know if there is any improvement.

At one month postoperatively, all electrodes had improvement in their thresholds (least improvement at El. 12), except El.11 (table 3); Significant improvement of threshold was found at El.2, 6, 8, 9 and 10 (the middle electrodes).

Comparing thresholds of NRT intraoperatively and three months postoperatively thresholds of all electrodes improved even El.11; Significant improvement was found at El.9 and 10.
Comparing thresholds of NRT one and three months postoperatively there was increase in threshold of El.2, El.4, El.6, El.8, El.9 and El.12,howerver this increase was not statistically significant except at El.8.

Tsuprun and Santi,(2001) attributed this increase to the cellular layer of tympanic covering cells along the Scala tympani that adhere to the thick matrix of the basilar membrane ,these cells possess phagocytic properties. It is possible that these cells react with the electrode by inducing foreign body reaction leading to the formation of a fibroblast cover encasing the $\mathrm{CI}$ electrode. A robust proliferation of these encasing fibroblasts could lead to increased electrode impedances that can result in lower performance.

Juiz et al. (1988) had the same result, they found significant improvement in mean ECAP threshold postoperatively and attributed this to insertion of electrode caused swelling of auditory nerve fibers which could lead to decrease in the neurons sensitivity to electrical signals, and the swelling was reversible shortly after the operation.

However this result is in disagreement with Muhammied et al. (2010) who found that no statistically significant correlation between intraoperative NRT and postoperative NRT, while they were predicting $\mathrm{C}$ and $\mathrm{T}$ level from NRT. They found that either intraoperative or postoperative NRT can be used, but this may be due to using a different implant (Nucleus 24).

Also, Wolf et al.(2015) result differ from this result in first measurement postoperative, they noticed increased telemetry between first and second week postoperative ,but by ten week ,the values had reduced, which may be 
due to previous onset of electrical stimulation.

Telmesani and Said (2016) agreed with this result in the difference between intraoperative and postoperative changes as they concluded that intraoperative thresholds demonstrated significant improvement relative to postoperative recording times, limiting the ability to use intraoperatively recorded ECAP thresholds to predict postoperative measurements.

Also, they agree with this study result in that postoperative changes in follow up as they stated that most electrodes undergo non-significant change in ECAP thresholds over time, and therefore thresholds obtained on the day of initial stimulation can be used to estimate the patients' map levels at any time.

Brown et al.(2010) agreed with this study result, they observed increase rather than decrease in the mean threshold of NRT for both pediatric and adult CI users between an "early" visit and a "late" visit postoperatively ,but this change in mean ECAP threshold was statistically significant although it was small change.

So, this study showed that NRT response may appear postoperatively while absent intraoperatively, there is significant improvement in NRT threshold postoperatively in comparison with threshold intraoperatively, mean threshold of NRT increase three months postoperatively in comparison with first postoperative measurement, however this increase was not statistically significant and therefore thresholds obtained on the day of initial stimulation can be used to estimate the patients' map levels at any time.

The main objective of this study was to prove that there will be improvement in NRT in postoperative follow up.

\section{Conclusion:}

-Absence of NRT response in some electrodes intraoperative does not mean that electrode must be out of function or outside the cochlea, as there are may be temporary causes of its absence such as air bubbles, oedema of tissue and thickness of skin flap above electronic package may also affect initial measurement.

-There is significant improvement in thresholds of NRT response postoperatively which was high intraoperatively.

-NRT threshold increase in postoperative follow up in comparison with first postoperative measurement but this increase isnot statistically significant.

\section{References}

1-Brown C, Abbas P, Etlert C, O'Brient S, Oleson J. Effects of longterm use of a cochlear implant on the electrically evoked compound action potential. J Am AcadAudiol. 2010 Jan;21(1):5-15.

2-Bower C, Martin P. Infant hearing screening. CurrOpinOtolaryngol Head Neck Surg 2008; 16(6):562-568.

\section{3-Chen J,Chuang A,Sprinzl G. impedance and electerically evokedcompound action potential (ECAP) drop within 24 hours after cochlear implantation .PLos ONE 2013; (8): 19-29.}

4-Clark G. Cochlear implants: fundamentals and applications New York: Springer-Verlag; 2003; 5:12:14.

5-Cosetti M, Shapiro W, Green J. Intraoperative neural response telemetry as a predictor of performance. OtolNeurotol 2010; 31:1095-1099. 
6-Goehring J, Hughes M, Baudhuin J.

How well do cochlear implant intraoperative impedance measures predict postoperative electrode function? Otol. Neurotol. 2013; 34: 239-244.

7-Grolman W, Maat A, Verdam F. Spread of excitation measurement $\mathrm{s}$ for the detection of electrode array foldovers: a prospective study comparing 3-dimensional rotational $\mathrm{x}$ ray and intraoperative spread of excitation measurements. OtolNeurotol 2009; 30:27-33.

\section{8-Juiz J.,Rueda J.\&Merchan J.} Reversible damage to the nerve fibers in the organ of corti after surgical opening of the cochlea in the rat .ActaOtolarngeal.1988;106: 29-33.

12-Tsuprun V, Santi P. Proteoglycan arrays in the cochlear basement membrane. Hear Res 2001;157: 65-76.

13-Vargas J, Sainz M, Roldan C, Alvarez I, de la Torre A. Long-term evolution of theelectrical stimulation levels for cochlear implant patients. ClinExpOtorhinolaryngol 2012; 5:194200.
9- Muhamimeed H., Fatma A, Osama H, Eba S., international journal of pediatric otorhinolaryngology 2010; 74 : 356-360.

10- Su G, Colesa D. \&Pfingst $B$. Effects of deafeningand cochlear implantation procedures on post implantation psychophysical electrical detection thresholds.Hear.Res.2008; 241, 65-72.

11- Telmesani L, Said N. Electrically evoked compound action potential (ECAP) in cochlear implant children: Changes in auditory nerve response in first year of cochlear implant use. Int $\mathbf{J}$ PediatrOtorhinolaryngol. 2016 Mar; 82: 28-33.

14-Wolf-Magele A,Schnabl J,Edlinger S,Pok S.M,Schoerg P,Sprinzl G.M.,postoperative changes in telemetry measurments after cochlear implantatgion and its impact on early activation.

Clin.Otolaryngol.2015;40:527-534. 